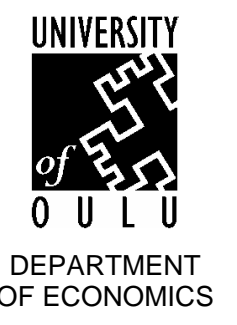

Working Papers

\title{
Comparing welfare effects of different regulation schemes: an application to the electricity distribution industry
}

\author{
Maria Kopsakangas-Savolainen \\ University of Oulu \\ and \\ Rauli Svento \\ University of Oulu
}

Working Paper No. 0901

March 2009

ISSN 1796-7961 
Department of Economics

University of Oulu

Working Paper No. 0901

\title{
Comparing welfare effects of different regulation schemes: an application to the electricity distribution industry
}

\begin{abstract}
We compare the welfare effects of different regulation schemes of electricity distribution utilities. The regulation schemes are price cap regulation, cost of service regulation, menu of cost-contingent contracts and simple menus of contracts. In our calculations we utilize the benchmarking information of firm specific costs. The firm specific cost information of Finnish electricity distribution utilities is obtained by using various Stochastic Frontier models. Our basic result is that welfare can be improved by changing the cost of service regulation scheme to the menu of contracts regulation. Welfare also increases in the case of price cap regulation. There is however, a significant difference among regulation regimes on how this improved welfare is distributed to consumers and producers.
\end{abstract}

JEL Classification: C13, C23, D60, D24, L51, L94.

Keywords: Welfare, regulation, benchmarking, stochastic frontier analysis, cost efficiency, heterogeneity, electricity distribution

Maria Kopsakangas-Savolainen

Department of Economics

University of Oulu

P.O.Box 4600

FIN-90014 University of Oulu

FINLAND

e-mail: maria.kopsakangas@oulu.fi
Rauli Svento

Department of Economics

University of Oulu

P.O.Box 4600

FIN-90014 University of Oulu

FINLAND

e-mail: rauli.svento@oulu.fi 


\section{Introduction}

It is generally known that fully informed regulators do not exist in reality. In most of the cases the regulated firm has more information about its costs and other factors and accordingly, the regulated firm may use its information advantage strategically in the regulatory process to increase its profits or to pursue other managerial goals, to the disadvantage of consumers. Many regulatory agencies have put lot of effort to reduce this information asymmetry. Theoretical research on regulation (especially incentive regulation) has also evolved and it has provided new information to regulators (see e.g. Laffont (1994), Laffont and Tirole (1986) and (1993), Armstrong, Cowan and Vickers (1994) and Armstrong and Sappington (2004)). Because the regulator has less information than the firms the regulated firms have strategic advantage. Generally any firm would like to convince the regulator that it is a "higher cost" firm than it actually is. By behaving like this the firm believes that the regulator sets higher prices (which increases firms' profits and removes welfare from consumers to the regulated firms).

When a social welfare maximizing regulator tries to distinguish between firms with high cost endowments and firms with low cost endowments it faces an adverse selection problem. One possible solution to this problem is to use firm's ex post realized costs to set regulated prices. This means that the regulator uses some form of "cost of service" (or rate of return) regulation. However, when the regulator in this way solves the adverse selection problem it leads to another problem, namely to the moral hazard problem. This is because the loss of the opportunity for the firm to earn extra profits reduces managerial effort and consequently less managerial effort increases the firm's realized costs. This leads to the situation where regulation actually increases the costs above their efficient levels.

The moral hazard problem may be solved by some form of incentive regulation (e.g. price cap regulation, revenue cap regulation or yardstick competition), but then full costs of adverse selection problem are incurred. The regulator is thus in a complicated situation. One problem connected to the price cap regulation is also the fact that price cap regulation is very weak at rent extraction for the benefit of consumers and society and it potentially leaves a lot of rent to the firm. This raises the question whether we could find a regulatory mechanism which will lie somewhere between these two extremes. The task of the regulator is hence to find such a mechanism that takes the social costs of adverse selection and moral hazard into account. One of these kinds of methods is menu of contracts regulation, where for each firm a menu of cost 
contingent contracts is offered and the firm can choose a contract which it prefers among the menu (see Laffont and Tirole (1986)).

In this paper we compare the welfare effects of different regulation schemes in electricity distribution utilities. ${ }^{1}$ We use Finnish data in our study. The four regulation schemes which we compare are price cap regulation, cost of service regulation, menu of cost-contingent contracts and simple menus of contracts. In our calculations we utilize the benchmarking information of firm specific costs. The firm specific cost information is obtained by using various models of Stochastic Frontier Analysis. Our basic result is that total welfare can be improved if we move from the cost of service regulation scheme to the menu of contracts regulation, simple menu on contracts or to the price cap regulation. There is however, a significant difference among regulation regimes on how this improved welfare is distributed to consumers and producers.

The rest of the paper is organized as follows: Chapter 2 gives an introduction of different regulation schemes and in chapter 3 the stochastic frontier models and their estimation is presented. In chapter 4 the calculated welfare effects are presented. Chapter 5 summarizes the findings.

\section{Different regulation regimes}

\subsection{Rate of return / Cost of service regulation}

The Rate of return (ROR) or cost of service regulation is the traditional approach to regulate monopolies. In the purest form of this regulation the rate of return is fixed to the costs. This means that the utility does not face the risk connected to input prices or other risks related to the costs. There are naturally both advantages and disadvantages connected to each regulatory method. The advantages of rate of return regulation are its relatively simple practical application in limiting monopoly pricing, the possibility to use second-best (e.g. RamseyBoiteux) or non-linear prices, the use of deliberate cross-subsidization ${ }^{2}$ and finally the rate hearings provide an opportunity for customers to express their views (see e.g. Liston (1993)). It has been also argued that an additional positive feature of this regulation method is better

\footnotetext{
${ }^{1}$ See Pint (1992) for comparing the welfare effects of price-cap and rate-of-return regulation in a stochastic-cost model.

${ }^{2}$ E.g. local telephone service at low rates (subsidized by long-distance service).
} 
certainty of long-term investments. Disadvantages connected to this regulation scheme (just to remark the most obvious ones) are that it does not give incentive to produce efficiently and if the allowed rate of return on capital is higher than the cost of capital an input bias (called the Averch-Johnson effect) follows. Rate of return regulation also typically entails high administrative costs (due to time-consuming hearings and requirement of considerable knowledge about the firm's costs). One further difficulty is in determining the "right" level of allowed rate of return which has been seen problematic. On the other hand it is not possible for the firms to gather excessive profits or to incure big losses. Formally the rate of return regulation $^{3}$ for firm i can be written as:

$$
P_{i, t}=(1+r) C_{i, t-1},
$$

where $\mathrm{P}$ is the allowed price at period $\mathrm{t}, \mathrm{r}$ is the allowed rate of return, and $\mathrm{C}$ is realized costs at period $\mathrm{t}-1$.

To summarize, the main reservation against this approach is clearly that it does not provide incentives for cost savings and efficiency improvements. It may also easily lead to overinvestments.

\subsection{Price cap regulation}

The price cap regulation has perhaps been the most significant alternative to the ROR regulation method in utility regulation. The price cap method was first proposed by Littlechild (1983) and it has since been adopted in the regulation of many industries (including telecommunication, gas distribution, water distribution, airline industry, railway industry and electricity) in the UK and other countries as well. ${ }^{4}$

In its purest form either the price or price path is fixed. This means that the utility faces the full risk connected to the input prices and demand. On the other hand utility has full incentive to reduce costs because it can keep all the benefits from cost reduction. This has been seen as the main advantage of this regulation scheme. The other advantages are relatively small administrative costs, non existence of input bias (A-J effect) and the fact that

\footnotetext{
${ }^{3}$ When the rate of return regulation is determined this way it is identical to the pure cost of service regulation where firm is allowed to add some fixed percent above its costs.

${ }^{4}$ For the description and discussion of price cap and rate-of-return regulation see also Armstrong et al. (2007), Joskow (2006) and Liston (1993).
} 
price ceilings on monopoly services prevent predatory pricings. Because of the differentiation of the price from costs and the fact that in pure price regulation the price does not react to any exogenous factor it is possible for the firm to gather excess profits or also to incur big financial losses. As in any regulatory scheme there exists also some disadvantages in this method. The disadvantages include the uncertainty about the service quality, the fact that potential benefits of e.g. Ramsey-Boiteux prices are ruled out, implementation of price cap can be difficult and there may be greater possibility for capturing the regulatory process by the firm (see e.g. Liston (1993)).

The price cap regulation essentially decouples the profits of the regulated utility from its costs by setting a price ceiling. This method is also referred to as the "RPI - X" model. In this model the price cap for each year is set based on the Retail Price Index and an efficiency factor X. Hence prices remain fixed for the rate period and the utility is allowed to keep the achieved cost savings. Formally the price ceiling for firm $i$ is set according to the following equation:

$P_{i, t}=P_{i, t-1} *\left(R P I-X_{i}\right)+/-Z_{i}$

According to the equation above the price ceiling $\mathrm{P}_{t}$ for each year is calculated based on the previous year's price ceiling $\mathrm{P}_{\mathrm{t}-1}$ adjusted by RPI minus the efficiency factor $\mathrm{X}$. The efficiency factor $\mathrm{X}$ is set by the regulator. In practice the price ceiling may be adjusted using a correction factor Z. This correction factor accounts for the effect of exogenous extraordinary events affecting the utility's costs.

The potential problems associated with the practical implementation of price cap regulation are connected to the price review procedure, to the commitment of regulating authority, to the quality and to the rules how to determine the $\mathrm{X}$ parameter (see e.g. Joskow (2006) and Jamasb and Pollitt (2001)).

\subsection{The Optimal Incentive Scheme}

It has been argued (see e.g. Laffont and Tirole (1986), (1993) and Joskow (2006)) that perhaps the optimal regulatory mechanism will lie somewhere between these two extremes i.e. between the pure cost of service (or rate of return) and pure price regulation. The regulation model will then have the form of either a profit sharing contract or a sliding scale 
mechanism (price that the regulated firm can charge is partially responsive to changes in realized costs and partially fixed ex ante). It has also been argued that more generally, by offering a menu of cost-contingent regulatory contracts with different cost sharing provisions, the regulator can do even better than if it offers only a single profit sharing contract (Laffont and Tirole 1993). The basic idea of the optimal incentive scheme is to make it profitable for a firm with low cost opportunities to choose relatively high powered incentive scheme (e.g. price or revenue cap regulation) and a firm with high cost opportunities a relatively lowpowered scheme (e.g. rate of return or cost of service regulation).

In the Laffont-Tirole model (1986) the firm chooses output and effort and after the costs are realized and observed, the planner rewards the firm according to the two observables, output and costs. Equivalently, the planner can ask the firm to reveal its true productivity parameter. Laffont and Tirole show that it is possible to construct such a incentive scheme that it induces the firm to tell the truth such that the level of effort is voluntarily optimally chosen by the firm. The incentive scheme is linear in costs and can be written as $T(\beta, C)=$ $\mathrm{s}^{*}(\beta)+\mathrm{K}(\beta)\left[\mathrm{C}^{*}(\beta)-\mathrm{C}\right]$, where $\mathrm{T}$ is net transfer to the firm, $\mathrm{s}^{*}$ is ex ante reward, $\mathrm{C}^{*}$ is ex ante cost, $\mathrm{C}$ is realized costs, $\beta$ is the productivity parameter and $K^{*}(\beta)=\frac{\psi^{\prime}\left[e^{*}(\beta)\right]}{q^{*}(\beta)}$, where $\mathrm{q}^{*}$ is optimal output, e* is optimal effort level and $\psi^{\prime}$ is marginal disutility of effort. Hence the reward depends on the announcement of the $\beta$ and the expost costs.

In practice the optimal allocation can be implemented by asking the firm to announce expected average costs and by making the transfer depend on the expected and realized average costs. The ex ante reward and the slope of the ex post bonus scheme decreases with the announced cost. Chu and Sappington (2009) consider a straightforward extension of Laffont and Tirole's model which allows the supplier to be able to reduce production more easily when cost are initially high than when they are initially low. Chu and Sappington also show how this extended model admits many of the forms of optimal contracts that prevail in practice.

The theory of a menu of cost-contingent regulatory contracts with different cost sharing provisions has two related problems when the practical implementation comes to question. These problems are firstly the fact that the economic logic and the underlying mathematics involved in calculating the optimal menu are quite complex, and secondly the issue that principal must be able to specify the agent's entire disutility of effort function in order to calculate the optimal menu. Consequently the model has not been widely used in practice or 
even in empirical applications of the theory. Because of these reasons we use a simplified version of this model in our calculations presented below in Chapter 4.

\subsection{Simple Menu of Contracts}

Rogerson (2003) shows that dramatically simpler menus which are easy to understand and calculate and which have lower informational requirements, can capture a substantial share of the gains achievable by the fully optimal complex menu. ${ }^{5}$ The problem for the principal (or regulator) is to find such a menu of contracts that minimizes his expected payment to the agent, subject to the constraint that all types of the agents accept a contract and produce the good. Rogerson uses the name "Fixed Price Cost Reimbursement" (FPCR) for a simple contract menu. Pure cost-reimbursement contracting corresponds to rate of return regulation and fixed-price contracting corresponds to price cap regulation. In his paper Rogerson shows that there is a unique optimal FPCR menu which solves the principal's cost minimization problem. In order to use this simple menu in real contracting situations, a principal would need to be able to have information on the cumulative distribution and density of costs if a cost-reimbursement contracts is used and the size of the efficiency gain that he believes would be induced by fixed-price contracting.

Rogerson also shows that in the procurement situation and for the uniform quadratic case, this FPCR menu captures at least 75 percent of the gains achievable by the fully optimal complex menu. Therefore considerably simpler menus with lower informational requirements can capture a substantial share of the gains achievable through using the fully optimal menu of contract.

The procedure to determine FPCR menu is the following: first, the principal offers the agent a menu of contracts specifying price as a function of costs, and then the agent decides which contract to accept. A theoretical lower bound on the principal's expected price is the price equal to procurement cost in the case he had full information of the type of the agent. The principal would minimize his price by offering to pay an agent of type $\mathrm{x}$ a fixed price equal to $\mathrm{x}-\mathrm{k}$, where $\mathrm{k}$ denotes the resulting surplus. If the agent accepts this contract, he reduces costs to the efficient level (or first-best level) and earns zero profits. The upper bound on the principal's expected price is the price which guarantees that agent will always produce

\footnotetext{
${ }^{5}$ See also Reichelstein (1992), Bower (1993), Sappington and Weisman (1996) and Gasmi et al. (1999) for studying the performance of simple mechanism in Laffont-Tirole type framework.
} 
the good i.e. principal will offer the agent a cost-reimbursement contract in which the principal promises to pay the agent a price equal to the measured cost of production. Under such a contract, agent has no incentive to cost reduction and earns again zero profits. The problem of the principal is to find the "cut-off type" $\theta$ so that his expected payment to the agent is minimized. The "cut-off type" is the highest type willing to accept the fixed price contract. Rogerson (2003) shows that if there exists an $x^{*} \in\left[x_{\min }, x_{\max }\right]$, which solves $\mathrm{F}\left(\mathrm{x}^{*}\right)=\mathrm{kf}\left(\mathrm{x}^{*}\right)$ then $\theta=\mathrm{x}^{*}$. However, if $\mathrm{F}(\mathrm{x})<\mathrm{kf}(\mathrm{x})$ for every $\mathrm{x} \in\left[x_{\min }, x_{\max }\right]$ then $\theta=\mathrm{x}_{\max }$. $\mathrm{F}(\mathrm{x})$ is the distribution function of $\mathrm{x}$ and $\mathrm{f}(\mathrm{x})$ is the density function of $\mathrm{x}$.

\section{Estimation for the efficiency costs}

\subsection{Stochastic Frontier Analysis and estimated model specifications}

We use Stochastic Frontier Analysis for the estimation of efficient costs which we need in order to calculate the welfare effects of the different regulation regimes presented in chapter 2. The literature concerning Stochastic frontier analysis and its applications is quite large and we refer the reader to see e.g. Kumbhakar and Lovell (2000), Pitt and Lee (1981), Schmidt and Sickles (1984), Greene (2005a, 2005b), Farsi, Filippini and Greene (2006) (2005) and Kopsakangas-Savolainen and Svento (2008)).

We estimate four modifications of the basic random and fixed stochastic frontier models by using Cobb-Douglas specifications. In the following models (3-6) we assume that the deterministic cost frontier takes the log-linear Cobb-Douglas form and linear homogeneity of cost frontier is attained through dividing all prices by input price. In each model total annual costs per kwh (C) is explained by distributed kilowatts (y), load factor (LF) number of customers $(C U)$ and labour and capital prices $\left(\mathrm{p}_{\mathrm{L}}, \mathrm{p}_{\mathrm{K}}\right)$.

Our benchmark model is the basic random effects (RE) model. We assume the random terms $\mathrm{v}$ and $\mathrm{u}$ to be normally and half normally distributed. The inefficiency term $(\mathrm{u})$ is time invariant in this model specification. The first of the estimated models which accounts heterogeneity (observed) is the RE model extended by the inclusion of a heterogeneity component into the mean of the distribution of $u_{i}$. We call this model as the REH model. Model TRE is the random parameter version of the RE model. Now, however, the inefficiency term $(\mathrm{u})$ is time variant. In the TRE model a firm specific random constant term 
is used. This model specification is what Greene (2005a) calls the true random effects model. Last model estimated is the True fixed effect model (TFE) proposed by Greene (2005a).

The estimated model specifications are

RE model

$\ln C_{i t}=\alpha+\beta_{y} \ln y_{i t}+\beta_{L F} \ln L F_{i t}+\beta_{C U} \ln C U_{i t}+\beta_{l} \ln p_{L i t}+\beta_{k} \ln p_{K i t}+\beta_{t} t+v_{i t}+u_{i}$

REH model

$\ln C_{i t}=\alpha+\beta_{y} \ln y_{i t}+\beta_{C U} \ln C U_{i t}+\beta_{l} \ln p_{L i t}+\beta_{k} \ln p_{K i t}+\beta_{t} t+v_{i t}+u_{i t}$

$v_{i t}=N\left(0, \sigma_{v}^{2}\right), \quad u_{i}=N^{+}\left(\mu_{i}, \sigma_{u}^{2}\right)$,

$\mu_{i}=\delta_{0}+\delta_{1} \ln L F_{i t}$,

TRE model

$\ln C_{i t}=\left(\alpha+w_{i}\right)+\beta_{y} \ln y_{i t}+\beta_{L F} \ln L F_{i t}+\beta_{C U} \ln C U_{i t}+\beta_{l} \ln p_{L i t}+\beta_{k} \ln p_{K i t}+\beta_{t} t+v_{i t}+u_{i t}$ $w_{i} \sim N\left(0, \delta_{v}^{2}\right)$

TFE model

$C_{i t}=\alpha_{i}+\beta_{y} \ln y_{i t}+\beta_{L F} \ln L F_{i t}+\beta_{C U} \ln C U_{i t}+\beta_{l} \ln p_{L i t}+\beta_{k} \ln p_{K i t}+\beta_{t} t+v_{i t}+u_{i t}$

All models are estimated by maximum likelihood. Since there exists no closed form solution for the TRE model it is estimated using a grid for $\mathrm{w}$. After a choice for $\mathrm{w}$ is made the model is estimated using maximum likelihood. The global optimum is the one with the highest likelihood over the w grid.

\subsection{The data}

The data used in this study consists of a panel of 76 electricity distribution utilities in Finland. It covers the 6-year period from 1997 to 2002. The data, which is unbalanced panel data, is collected from the statistics of the Finnish Electricity Market Authority. ${ }^{6}$ Distribution utilities which are owned by industrial enterprises are excluded from this study. The relative size of

\footnotetext{
${ }^{6}$ The data is available in the address www.energiamarkkinavirasto.fi
} 
the distribution utilities varies significantly which may explain part of the quite large variations in costs.

Table 1 gives the summary of descriptive statistics of the variables used in this paper. We have used constant Euro prices by converting all money values to the year 1997 by using the retail price index. Costs $(\mathrm{C})$ are expressed as average costs calculated as total annual costs per $\mathrm{kWh}$ delivered. This includes the delivery to the final customers and the delivery to the networks. The costs of losses are excluded because of the lack of reliable data. Annual output (y) is measured in Gwh and as can be seen from Table 1 it varies quite significantly since the range runs from very small local utilities to the relative large utilities operating on urban areas. Annual labour price $\mathrm{p}_{1}$ is calculated by dividing total annual labour cost by the average number of employees. The capital price $p_{\mathrm{k}}$ is calculated by dividing the annual capital expenditures by the value of capital stock. Total capital expenditure is calculated as residual costs. We have approximated the capital stock by the present value of the network. The present value of the network is calculated using the information of annual inventories and replacement value of the network. The price of the input power $p_{p}$ is in most cases computational. ${ }^{7}$ This is particularly the case when the distribution utility receives part of its delivered energy directly from the local generator and purchases only part of its total delivered energy. Load Factor (LF) is the ratio of the average load supplied during a designated period to the peak load occurring in that period, in kilowatts. Simply, the load factor is the actual amount of kilowatt-hours delivered on a system in a designated period of time as opposed to the total possible kilowatt-hours that could be delivered on a system in a designated period of time. ${ }^{8}$

\footnotetext{
${ }^{7}$ The input price is computed when distribution utility purchases only part of its delivered energy. The calculations are based on the market place payment, payment to the other companies' network and on the relative share of the received power and delivered power. It is important to correct the input price when only part of the delivered electricity is purchased. Otherwise it distorts the cost structure of these companies.

${ }^{8}$ Utilities are generally interested in increasing load factors on their systems. A high load factor indicates high usage of the system's equipment and is a measure of efficiency. High load factor customers are normally very desirable from a utility's point of view. Using a year as the designated period, the load factor is calculated by dividing the kilowatt-hours delivered during the year by the peak load for the year times the total number or hours during the year.
} 
Table 1 Descriptive statistics (456 observations)

\begin{tabular}{|c|c|c|c|c|}
\hline & Mean & $\begin{array}{l}\text { Standard } \\
\text { Deviation }\end{array}$ & Minimum & Maximum \\
\hline $\begin{array}{l}\text { Total annual } \\
\text { costs (C)per } \\
\text { kWh output } \\
\text { (cents) }\end{array}$ & 1.74 & .40 & .77 & 2.97 \\
\hline $\begin{array}{l}\text { Annual output } \\
\text { (y) in GWh }\end{array}$ & 433.47 & 727.87 & 11.83 & 5825.90 \\
\hline $\begin{array}{l}\text { Number of } \\
\text { customers } \\
\text { (CU) }\end{array}$ & 27494 & 42784 & 1109 & 324197 \\
\hline $\begin{array}{l}\text { Load Factor } \\
(\text { LF) }\end{array}$ & 0.499 & $.773 E-01$ & .191 & .866 \\
\hline $\begin{array}{l}\text { Annual labour } \\
\text { price }\left(p_{1}\right) \text { per } \\
\text { employee } \\
(1000 €)\end{array}$ & 28.39 & 7.75 & 8.14 & 53.00 \\
\hline $\begin{array}{l}\text { Capital price } \\
\left(p_{k}\right)(1000 €)\end{array}$ & .103 & .058 & .020 & .353 \\
\hline $\begin{array}{l}\text { Price of } \\
\text { input power } \\
\left(p_{p}\right) \text { per kWh }\end{array}$ & .36 & .14 & .09 & 1.06 \\
\hline
\end{tabular}

\subsection{SFA Results}

In Table 2 results for the estimations are presented. ${ }^{9}$ The endogenous explained variable is total annual costs per kWh in 1997 cents. The linear homogeneity normalising price divider is the input power price $\mathrm{p}_{\mathrm{p}}$.

The first observation on the estimation results is that all coefficients of the frontier are highly significant ${ }^{10}$ and have expected signs. Both price effects have positive signs in the all model specifications and the capital price effect is larger in absolute terms in all other models than in the TFE model. The high capital price estimates are understandable due to capital

\footnotetext{
${ }^{9}$ We have used LIMDEP 8.0 and 9.0 in estimations (see Greene 2002 and 2007).

${ }^{10}$ Except LF in the RE model.
} 
intensity of distribution networks. The sign of output (y) estimator is negative in all specifications which is expected since the explained variable is total costs per $\mathrm{kWh}$. As the distributed quantity increases the unit costs decrease up to the point of minimum efficient scale. Also the sign of the time estimate is negative. This indicates that there has been technological development which has decreased the total unit costs.

It is also notable that in the basic random effects model (RE) the constant term is considerably smaller than the corresponding averages from the REH specification. This being the case the basic RE model estimates the frontier to be down to the left compared to the extended RE model. The estimate of LF is significantly smaller in REH model than in other specifications. The other parameter estimates are relatively close to each other.

The variance parameter of the underlying distribution of $u_{i}, \sigma_{u}$, is estimated as .353 (see Table 3) in basic random effects model (RE). In the extended version of RE (REH) as well as in the randomized version TRE and TFE the counterparts are .150, .096, and .101. These point out that some of the variation in the inefficiency in the original RE model can be explained as heterogeneity. Based on this notification we can expect the estimated inefficiencies to diminish. According to BIC-criteria it seems that Greene's (2005a) true random effects model (model TRE in our case) fits the data best. 
Table 2. Cost frontier parameters of models $3-6$

\begin{tabular}{|c|c|c|c|c|c|c|c|c|}
\hline & $\mathbf{R E}$ & & REH & & TRE & & TFE & \\
\hline & Coeff. & Std.er & Coeff & Std.er & Coeff. & Std.er & Coeff. & Std.er \\
\hline Constant & -1.614 & 6.272 & -2.326 & $.126+07$ & -1.484 & .049 & & \\
\hline LnCU & .584 & .054 & .603 & .052 & .644 & .010 & .569 & .016 \\
\hline $\operatorname{LnLF}^{11}$ & -057 & .050 & -2.550 & .675 & -.032 & .014 & -.352 & .033 \\
\hline $\operatorname{lnp} p_{1}$ & .297 & .008 & .288 & .007 & .300 & .004 & .445 & .014 \\
\hline $\mathrm{T}$ & -.014 & .002 & -.014 & .002 & .015 & .001 & -.017 & .005 \\
\hline \multicolumn{9}{|l|}{ for distr. ${ }^{12}$} \\
\hline Log & 389.40 & & 413.52 & & 416.79 & & 302.60 & \\
\hline \multicolumn{9}{|l|}{ likelihood } \\
\hline N & 419 & & 419 & & 419 & & 419 & \\
\hline BIC-criteria ${ }^{13}$ & -736 & & -779 & & -791 & & -569 & \\
\hline
\end{tabular}

\footnotetext{
${ }^{11}$ In the model REH this is refers to the third equation in model (4).

${ }^{12}$ Scale parameter for distributions of random parameters.

${ }^{13} \mathrm{BIC}=-2 * \log \mathrm{L}+\mathrm{Q} * \log \mathrm{N}$, where $\mathrm{Q}$ is the number of parameters.
} 
In Table 3 we present statistics of inefficiency scores. The scores represent the percentage deviation from a minimum level that would have been incurred if the company had operated as best-practice (or cost efficient) based on our data.

These basic statistics clearly show that the models REH, TRE and TFE capture the firm specific heterogeneity into the cost frontier allowing the inefficiency distribution move to the left and become more concise. Also the distribution of the frontier in randomized specifications is more concise. Another clear observation is that TFE produces clearly different inefficiency scores than either the basic RE model or the random parameterized versions of the RE model. The difference among basic RE model inefficiency scores and those which TFE model produces can be explained by the clearly different model assumptions. First difference is the assumption of time varying inefficiency. Both RE and REH models assume constant inefficiency over time. The second difference is that in TFE correlation between firm specific effects and explanatory variables is allowed. This is not the case for the basic RE model. Third clear difference is that in the basic RE model any unobserved firm-specific differences are interpreted as inefficiency. Given that in electricity distribution a considerable part of the unobserved heterogeneity is related to network characteristics and is very likely beyond the firm's own control, the inefficiency estimates can be overestimated in RE models. All these three distinguishing assumptions among TFE and RE models can be observed from our inefficiency estimates. It is notable that the variance of the frontier in TFE model is rather big (.165) which shows that the model does not produce robust estimates for the frontier. This can be due to the rather short panel of the data or insufficient number of observations.

When we compare the basic random effect model to the random parameterized versions of RE model one observation to note is that mean inefficiency estimates clearly diminish. This can be explained by the fact that in the random parameterized models unobserved heterogeneity is not appearing as inefficiency. Also the inefficiency scores among TFE and random parameterized versions of the RE model differs somewhat. Even thought the maximum inefficiency score is clearly smaller in TFE model the mean of inefficiency is higher in TFE model than in model TRE. However, the mean of inefficiency is clearly closer each other among the TFE model and the random parameterized version of the RE model than among the basic RE model and its parameterized versions. 
Table 3. Statistics of inefficiency scores ${ }^{14}$

\begin{tabular}{|c|c|c|c|c|}
\hline & $\mathrm{RE}$ & REH & TRE & TFE \\
\hline Minimum & $.972-01$ & $.419-01$ & $.117-01$ & $.575-01$ \\
\hline Maximum & .782 & .481 & .450 & .142 \\
\hline Mean & .327 & .141 & $.737-01$ & $.775-01$ \\
\hline $\begin{array}{l}\text { Std.Dev. of } \\
\qquad E\left[u_{i} \mid \varepsilon_{i}\right]\end{array}$ & .130 & $.738-01$ & $.470-01$ & $.948-02$ \\
\hline$\sigma(v)$ & .068 & .067 & .032 & .165 \\
\hline$\sigma(u)$ & .353 & .150 & .096 & 101 \\
\hline
\end{tabular}

\section{Welfare effects}

The effects of the changes in regulation schemes with respect to the welfare are calculated by using the empirical cost inefficiency information (in determining the size of the efficiency gain) described in previous section. We have used all model specifications estimated. In the calculations we have assumed constant elasticity of demand with the elasticity value of $-0,35$.

The overall welfare change is calculated as the sum of the change in producer and consumer surplus. The welfare changes are reported in Table 5. The changes in consumer and producer surpluses can be specified as follows. The change in consumer surplus can be written as the line integral.

$$
\Delta C S=\int_{P_{C}}^{P_{N}} D^{-1}(Q) d Q
$$

\footnotetext{
${ }^{14}$ On the estimation of inefficiency in the stochastic frontier models see Jondrow et. al (1982)
} 
where $\mathrm{P}_{C}$ is the price under cost of service regulation, $\mathrm{P}_{\mathrm{N}}$ is the new price under either the price cap, menu of contracts ${ }^{15}$ or simple menu of contracts regulation, $\mathrm{D}^{-1}$ is the constant elasticity inverse demand function and Q is distributed total energy.

The corresponding change in producer's surplus is:

$$
\Delta P S=\left(P_{N i} Q_{N i}-C\left(Q_{N i}\right)\right)-\left(P_{C i} Q_{C i}-C\left(Q_{C i}\right)\right)
$$

Therefore, the change of total surplus is

$$
\Delta C S+\Delta P S=\int_{P_{C}}^{P_{N}} D^{-1}(Q) d Q+\left[\left(P_{N i} Q_{N i}-C\left(Q_{N i}\right)\right)-\left(P_{C i} Q_{C i}-C\left(Q_{C i}\right)\right)\right]
$$

where the new volume $\mathrm{Q}_{\mathrm{N}}$ is the supply and demand equilibrating quantity at the new price $\mathrm{P}_{\mathrm{N}}$. This assumption can be made because real time demand and supply must always equal each other in electricity distribution.

The following example illustrates the idea (and value of offering a menu of regulatory contracts) more detailed. Assume that there are two options, a fixed price contract (i.e. price regulation) or a cost-of-service contract, for the regulated firm to choose. If the fixed price contract is too demanding (for example violates the firm's budget constraint) the firm will choose the cost-of-service contract. On the other hand, if the firm is a very low-cost supplier it can choose the fixed price contract and more rents will be gathered.

The range of options can be illustrated as follows. Consider a regulatory process in which the firm's allowed price $P$ is determined based on a component of efficient costs of the highest type, $\mathrm{C}^{*}$, and on a component that is based on the firm's realised costs $C$. Then the allowed price is determined according to following equation:

$$
P_{i, t}=a C_{t-1}^{*}+(1-a) C_{i, t-1}
$$

\footnotetext{
${ }^{15}$ We us the name "menu of contracts" for our application of the incentive contract scheme.
} 
where $a$ is the sharing parameter that defines the responsiveness of the firm's allowed price to the realised costs, $t$ refers to time and $i$ to the firm in question. In the case of fixed price contract (price or price cap regulation) $a=1$ whereas in the case of pure cost-of -service (or ROR) regulation, assuming that the regulator can observe the firm's expenditures but not evaluate their efficiency, $a=0$. The profit sharing contract (or contracts of menu on our case) emerges with $0<a<1$.

Laffont-Tirole ((1986) and (1993)) show that it is socially optimal for the regulator to offer a menu of contracts with different combinations of responsiveness parameters. This should drive the firms with low true cost opportunities to choose a high powered scheme ( $a$ close to 1 ) and consequently firms whose true (efficient) cost are high to choose a lower powered incentive scheme ( $a$ close to zero).

In our calculations we have utilized our SFA estimation results in order to determine the firm specific efficient cost levels. Thus the firm specific efficiency estimations are used also in determining the efficient costs of the highest type $\mathrm{C}^{*}$ (see equation 10). We assume that each firm chooses the efficiency level which maximizes its profits. In price cap regulation the value of parameter $a$ is equal to 1 for each firm and the $\mathrm{C}^{*}$ is obtained by utilizing the SFA results. Now the profit maximizing strategy for each firm is to produce at efficient costs. In the cost of service regulations (which acts as benchmark model in our welfare calculations) the value of parameter $a$ is equal to zero for each firm and consequently firms produce at zero profits.

The game behind the contracts of menu in our application is as follows: first the regulator announces the regulation rule i.e. the rules according to which the value of parameter $a$ is determined and then the firm decides what efficiency level to choose (and we assume that it chooses the efficiency level which maximizes its profits). According to the announced rule for the most efficient firm the value of $a$ is equal to 1 and thus this firm is allowed to set price such that it equals the efficient cost of the highest cost type. For the most inefficient firm the value of parameter $a$ is equal to zero and consequently the price is equal to its realized costs and the firm earns zero profits. For firms between the most efficient and most inefficient firms the value of parameter a is set such that it is bigger for the more efficient firms than to those which are more inefficient compared to the other firms. In determining this relative efficiency value we have used our firm specific inefficiency estimates presented in the previous section. 
The price determined by the simple menu of contracts is calculated according to the rule described in chapter 2.4. According to that rule the objective of the regulator is to choose the so called "cut-off type" such that the cost of the regulator is minimized if it should cover the procurement costs. The "cut-off type" is the highest type willing to accept the price cap contract. The cut-off type $(\theta)$ is found by solving the equation $\mathrm{F}\left(\mathrm{x}^{*}\right)=\mathrm{kf}\left(\mathrm{x}^{*}\right)$ (then $\left.\theta=\mathrm{x}^{*}\right)$, where $\mathrm{x}$ is the agent's type, $\mathrm{F}(\mathrm{x})$ is the distribution function of $\mathrm{x}$ and $\mathrm{f}(\mathrm{x})$ is the density function of $\mathrm{x}$. In the simple menu of contracts the firm can choose between either price cap or cost of service regulation. Now each firm more or as efficient as the cut-off type firm maximizes it profits by choosing price cap contract (parameter $a$ equal to 1 ) and the best strategy for rest of the firms is to choose cost of service regulation (parameter $a$ equal to zero).

Based on these regulation schemes we are able to calculate the total welfare changes using our firm specific results on efficiency improvement potentials. The results for all four SFA model types (see equations 3-6) are presented in Table 4.

Table4. Change in welfare (TS $=P S+C S)$, Cost of service regulation ${ }^{16}$ as benchmark, million€

\begin{tabular}{|c|c|c|c|c|c|c|c|c|c|}
\hline \multirow[t]{2}{*}{$\begin{array}{l}\text { SFA } \\
\text { model }\end{array}$} & \multicolumn{3}{|c|}{ Price cap } & \multicolumn{3}{|c|}{$\begin{array}{l}\text { Menu of } \\
\text { Contracts }\end{array}$} & \multicolumn{3}{|c|}{$\begin{array}{l}\text { Simple menu of } \\
\text { contracts }\end{array}$} \\
\hline & $\Delta \mathrm{TS}$ & $\Delta \mathrm{PS}$ & $\Delta \mathrm{CS}$ & $\Delta \mathrm{TS}$ & $\Delta \mathrm{PS}$ & $\Delta \mathrm{CS}$ & $\Delta \mathrm{TS}$ & $\Delta \mathrm{PS}$ & $\Delta \mathrm{CS}$ \\
\hline $\mathrm{RE}$ & 177,8 & 240,9 & $-63,1$ & 194,4 & 150,0 & 44,4 & 144,43 & 70,6 & 73,9 \\
\hline REH & 49,6 & 234,2 & $-184,5$ & 61,5 & 184,1 & $-122,6$ & 25,9 & 10,4 & 15,6 \\
\hline TRE & 5,6 & 239,7 & $-234,1$ & 25,8 & 163,6 & $-137,8$ & 6,4 & 4,5 & 1,9 \\
\hline TFE & 8,3 & 235,5 & $-227,2$ & 14,7 & 207,4 & $-192,7$ & 3,6 & 1,4 & 2,2 \\
\hline
\end{tabular}

Changing the regulation scheme from cost of service to whatever other regulation regime presented above results in a significant welfare improvement. However, there is clear difference how different regulation schemes divide welfare to producers and consumers. In the case of menu of contracts both the producer surplus and concumer surplus increase if the efficient levels of the firms costs are determined by using the values of random effects (RE) model. If the possibilities of the efficiency

\footnotetext{
${ }^{16}$ We have used $4 \%$ for the $r$ in cost of service regulation (see equation (1)).
} 
improvements are determined according to the REH, TRE or TFE models producer surplus clearly increases but the consumer surplus decreases. This is due to fact that the efficiency improvent possibilities accoring to the REH, TRE, and TFE models are smaller than according to the model RE and consequently the efficient cost of the highes type $C^{*}$ (see equation 10) is quite high. This raises the average level of the allowed price and hence removes the welfare from the consumers to the producers. This result is even more clear in the case of price cap regulation where all firms are allowed to set the price equal to the efficient cost of the highest type (parameter $a$ is equal to 1 for every firm). The only regulation scheme which improves both producer and consumer welfare regardless of the model used in efficiency estimations is the simple menu of contracts. However, the overall welfare improvement is smaller than resulting from the price cap regulation or menu of contracts regulation. If the regulator is interested only in maximising total welfare it should choose menu of contracts regulation. However, if the regulator is interested more on consumer welfare and whishes to see lower overall prices it should set the regulation accoring to the simple menu of contracts. It is however clear that our results support the theory and changing the regulation method of network prices from traditional cost of service regulation it is possible to considerably improve social welfare.

\section{Conclusions}

The purpose of this study was to analyse whether it is possible to improve social welfare by changing the regulation scheme of electricity distribution. A great deal of theoretical research has been conducted concerning different regulation methods but the connections of the regulation theory to the real regulatory processes have been seen problematic. In this paper we combine the theory of different regulation schemes to the firm specific cost information of electricity distribution utilities obtained by using various Stochastic Frontier models. According to our results - consistently with the theory - price cap regulation solves the problem of moral hazard and welfare improves if we move from cost of service regulation to the price cap regulation. However, in price cap regulation the problem of adverse selection remains unsolved. According to theory the menu of contracts regulation should solve both the moral hazard and adverse selection problems. Our empirical results support this. Welfare can be significantly improved by removing from the pure cost based regulation to the 
menu of contracts regulation. Notable is that welfare increases in all model specifications. However there are significant differences among regulation schemes on how improved welfare is distributed to consumers and producers.

\section{Acknowledgements}

We thank participants of seminars in Yokohama National University Department of Economics, March 2008, Annual Meeting of Finnish Society of Economists, February 2008 and Oulu University Department of Economics, December 2007. All remaining errors are ours.

\section{References}

Amstrong, M., Cowan, S. and Vickers, J. (1994). Regulatory Reform: Economic Analysis and British Experience, Cambridge, MA: MIT Press.

Armstrong, M. and Sappington, D.E.M. (2004). Toward a Synthesis of Models of Regulatory Policy Design with Limited Information, Journal of Regulatory Economics, 26 (1), 5-21.

Armstrong, M. and Sappington, D.E.M. (2007). In: Armstrong, Porter, R. (Eds). Recent Developments in the Theory of Regulation in handbook of Industrial Organization 3. North Holland.

Bower, A. G. (1993). Procurement Policy and Contracting Efficiency. International Economic Review, vol 34 (4), pp. 873-901.

Chu, L. Y. and Sappington, D. E. M. (2009). "Procurement contracts: Theory vs. practice", International Journal of Industrial Organization 27, 51-59.

Farsi, M., Filippini, M. and W. Greene (2005). "Efficiency measurement in network industries: Application to the swiss railway Companies", The Journal of Regulatory Economics 28 (1), 69-90.

Farsi, M., Filippini, M. and W. Greene (2006). "Application of Panel Data Models in Benchmarking Analysis of the Electricity Distribution Sector", Annals of Public and cooperative Economics, 77(3), 271-290.

Gasmi, F., Laffont, J-J, and Sharkey W.W. (1999) Empirical Evaluation of Regulatory Regimes in Local Telecommunications Markets. Journal of Economics and management Strategy, Vol. 8(1), pp. 61-94.

Greene, W., 2002. LIMDEP version 8.0, Econometric Modeling Guide, Volume 2, Econometric Software, Inc. Plainview, NY, USA.

Greene, W., (2007). LIMDEP version 9.0, Econometric Modelling Guide, Econometric Software, Inc. Plainview, NY, USA.

Greene, W., 2004. Distinguishing between heterogeneity and inefficiency: stochastic frontier analysis of the World Health Organization's panel data on national health care systems. Health Economics 30. 959-980.

Greene, W. (2005a). "Reconsidering heterogeneity in panel data estimators of the stochastic frontier model", Journal of Econometrics 126, 269-303.

Greene, W. (2005b). "Fixed and Random Effects in Stochastic Frontier Models", Journal of Productivity Analysis 23, 7-32.

Jamasb, T. and Pollitt, M. (2001). Benchmarking and Regulation: International Electricity Experience, Utilities Policy 9, 107-130.

Jondrow, J., Lovell, C.A.K., Materov, I., Schmidt, P., 1982. On the estimation of technical inefficiency in the stochastic frontier production function model. Journal of Econometrics 19, 233-238.

Joskow, P. (2006). Incentive Regulation in Theory and Practice: Electricity Distribution and Transmission networks, MIT, mimeo. 
Kopsakangas-Savolainen, M. and Svento, R. (2008) "Estimation of cost-effectiveness of the Finnish electricity distribution utilities", Energy Economics, 30, 212-229.

Kumbhakar, S. C., Lovell, C.A.K., 2000. Stochastic frontier analysis, Cambridge, Cambridge University Press.

Laffont, J-J and Tirole, J. (1986). Using Cost Observation to Regulate Firms, The Journal of Political Economy, Vol. 94, No. 3, pp. 614-641.

Laffont, J-J and Tirole, J. (1993). A Theory of Incentives in Regulation and Procurement, Cambridge, MA: MIT Press.

Laffont, J-J(1994). The New Economics of Regulation Ten Years After. Econometrica, Vol. 62, No. 3, pp. 507-537.

Liston, C. (1993). Price-Cap versus Rate-of-Return Regulation, Journal of Regulatory Economics, 5, 25-48.

Littlechild, S. C. (1983). Regulation of British Telecommunications' Profitability, Report to the Secretary of State, Department of Industry, London: Her Majesty's Stationery Office.

Pint, E.M. (1992) Price-cap versus rate-of-retrun regulaiton in a stochatic-cost model, RAND Journal of Economics, Vol. 23, iss. 4.

Pitt, M., Lee, L., 1981. The Measurement and Sources of Technical Inefficiency in Indonesian Weaving Industry. Journal of Development Economics 9, 43-64.

Reichelstein, S. (1992). Constructing Incentive Schemes for Government Contracts. An Application of Agency Theory. Accounting Review, Vol. 67 (2), pp. 712-31.

Rogerson, W. P. (2003). Simple Menus of Contracts in Cost-Based Producurement and Regulation, The American Economic Review, Vol. 93, No. 3, pp. 919-926.

Sappington D.E.M. and Weisman, D. L. (1996). Designing incentive regulations for the telecommunications industry. Washington, DC:AEI Press.

Schmidt, P., and Sickles, R.E. (1984). "Production Frontiers and Panel Data", Journal of Business and Economic Statistics, 2: 367-374. 